\title{
Development of a Lightweight Low-Carbon Footprint Concrete Containing Recycled Waste Materials
}

\author{
S. Talukdar, S. T. Islam, and N. Banthia \\ Department of Civil Engineering, University of British Columbia, 1012J-6250 Applied Science Lane, Vancouver, BC, Canada V6T $1 Z 4$
}

Correspondence should be addressed to S. Talukdar, sudip@civil.ubc.ca

Received 4 April 2011; Revised 27 July 2011; Accepted 27 July 2011

Academic Editor: Monica Prezzi

Copyright () 2011 S. Talukdar et al. This is an open access article distributed under the Creative Commons Attribution License, which permits unrestricted use, distribution, and reproduction in any medium, provided the original work is properly cited.

Use of any recycled material helps to maintain a greener environment by keeping waste materials out of the landfills. Recycling practices also can decrease the environmental and economical impact of manufacturing the materials from virgin resources, which reduces the overall carbon footprint of industrial materials and processes. This study examined the use of waste materials such as crushed glass, ground tire rubber, and recycled aggregate in concrete. Compressive strength and elastic modulus were the primary parameters of interest. Results demonstrated that ground tire rubber introduced significant amounts of air into the mix and adversely affected the strength. The introduction of a defoamer was able to successfully remove part of the excess air from the mix, but the proportional strength improvements were not noted implying that air left in the defoamed mixture had undesirable characteristics. Freeze-thaw tests were next performed to understand the nature of air in the defoamed mixtures, and results demonstrated that this air is not helpful in resisting freeze-thaw resistance either. Overall, while lightweight, low-carbon footprint concrete materials seem possible from recycled materials, significant further optimization remains possible.

\section{Introduction}

Construction materials are increasingly judged by their ecological impact. Presently, the industry is concentrating on reducing the ecological footprint of concrete by looking at ways of making it "greener" [1]. Consequently, the use of recycled materials for coarse and fine aggregate is being actively encouraged.

Construction and demolition waste constitutes a major portion of all generated solid waste, with 200-300 million tons generated annually in the United States alone. The traditional disposal of these large amounts of waste in landfills is no longer an acceptable option. Coupled with the increasing scarcity of suitable aggregate, the pressure is severe to find an acceptable replacement for virgin aggregate. Use of recycled concrete aggregate (RCA) from the demolition of old structures could be an acceptable solution [2]. There are some well-known technical problems of incorporating RCA into mixes, such as the presence of contaminants and deleterious materials which affect the strength and durability of the final mix. There is also the possibility of cement reacting with the aggregate itself. For example, if crushed glass is used as a substitute for fine aggregate, then there is the possibility of an alkali silica reaction between the paste and the glass. However, experience shows that if the recycled aggregate is cleaned, sorted, and selected properly, then it can be used as an acceptable substitute for virgin coarse aggregate.

Fine and coarse aggregates traditionally account for a very small amount of $\mathrm{CO}_{2}$ emissions during production of concrete even though they usually constitute more than $2 / 3$ of the concrete volume. Manufacturing of fine and coarse aggregates have less emissions than production of cementitious binders despite quarrying that entails blasting, crushing, screening, haulage, and stockpiling of aggregates. Therefore, the most effective way of lowering the carbon footprint of concrete is to reduce the cement concrete in the mix. However, $\mathrm{CO}_{2}$ emissions due to demolition and reuse are a fraction of those compared to the production of virgin aggregate [3]. Furthermore, the stockpiles of recycled aggregate are generally closer to the construction site than that of virgin aggregate, which generally is quarried and 
transported from long distances [2]. In this respect, use of recycled aggregates to reduce carbon footprint should be encouraged.

The United States generates approximately 242 million scrap tires per year, and the US Environmental Protection Agency estimates that 2-3 billion scrap tires have already accumulated in illegal stockpiles or uncontrolled tire dumps throughout the country, with millions more scattered around in the natural environment [4]. It is essential that innovative solutions be developed to deal with this excess material to prevent it from becoming an environmental nuisance.

A sustainable proposition is to use scrap tires in concrete mixtures. Such a study was undertaken in the research reported here. Coarse aggregate was replaced with a high fraction of ground tire rubber, and the role of a defoaming agent was examined. Next, ground tire rubber was combined with crushed glass and recycled aggregate to further reduce the carbon footprint.

\section{Previous Work}

There have been countless number of studies which have looked at the properties of concrete containing various types and quantities of recycled coarse and fine aggregate. Properties such as chemical stability [5], physical durability [6], workability [7], strength [8], permeability [9], and shrinkage resistance [10] have been examined. A general consensus between these studies is that concrete containing recycled coarse aggregate which are properly cleaned, and in quantities no more than $50 \%$ replacement of virgin aggregate would have adequate durability, workability, and strength when compared with concrete containing 100\% virgin aggregate. Concrete containing recycled aggregate is expected to display slightly more shrinkage than that containing virgin aggregate only [10]. Permeability of concrete containing recycled aggregate at $\mathrm{w} / \mathrm{c}$ ratios same as that of concrete containing only virgin aggregate is also expected to increase [9]. With regards to chemical stability, it is important that waste aggregates being used do not contain reactive silica in order to avoid alkali-silica reaction (ASR) in the final product.

Waste glass constitutes a problem for solid waste disposal in many municipalities. The current practice is still to landfill most of it. Since glass is usually not biodegradable, landfills do not provide an environment-friendly solution. Consequently, there is a strong need to utilize/recycle waste glasses. One option is to crush and grade it and use it as a replacement for fine aggregate in a concrete mix.

As with waste recycled aggregates, it is very important that the glass used be silica-free in order to avoid ASR in the final composite. If this basic criterion is met, past studies indicate that recycled waste glass is an acceptable material to be used in concrete. There tends to be a slight decrease in compressive strength as the fraction of recycled glass is increased in a mix, and other properties such as air content and mix are dependent on the shape of the individual grains of the crushed glass $[5,11,12]$.

The idea of using recycled scrap tires in concrete has been around for some time. Earlier, research on the use of worn out tires was concentrated in asphalt mix design. However, it soon became apparent that the asphalt industry can only absorb $30 \%-40 \%$ of scrap tires generated [13], and so, emphasis has been slowly shifting to Portland cement concrete mix designs. Properties, testing and design of rubber as an engineering material in Portland Cement concrete were investigated as early as 1960 [14]. A comprehensive summary of the properties and application of concrete containing scrap tire rubber was presented by Siddique and Naik [15] and Nehdi and Khan [16].

Hernández-Olivares et al. [17], Huang et al. [18], Li et al. [4], Ganjian et al. [19], Toutanji [20], Batayneh et al. [21], Kahloo et al. [22], and Mohammed [23] conducted studies which included observation and modeling of the mechanical properties of recycled shredded tire concrete composites. The general trend observed was that as the percent content of tire rubber increases, the strength of the mix decreases. This is most likely due to the increase in the entrapped air in the concrete mix due to the tire. It was also noted that such composites exhibit large displacement and deformations, thereby generally increasing toughness, which is most likely due to the fact the rubber aggregate has the ability to withstand large deformations. Savas et al. [24] reported that the freeze-thaw durability of concrete with ground waste tire rubber deteriorated as the percent of ground rubber increases.

Many studies have reported that scrap tires increase the amount of entrapped air in concrete $[25,26]$. The reasons often cited are the rough rubber surfaces that entrap air, the nonpolar nature of rubber itself and its tendency to be hydrophobic. Several attempts have been made to improve the hydrophilicity of rubber, and the most promising one thus far appears to be soaking the rubber in an $\mathrm{NaOH}$ solution for short periods of time [15].

\section{Material and Methods}

Given that scrap tire entraps excessive amounts of air, the primary objectives of the study was to investigate the effectiveness of using a defoamer to reduce the air in mixes containing ground tire rubber. Having successfully achieved a reduction in the air content, ground tire rubber was then combined with other recycled materials such as recycled aggregate and crushed glass to further reduce the carbon footprint. The four concrete mixtures investigated (M0, M1, M2, and M3) are given in Table 1. Their fresh properties are also listed therein.

CSA Type 10 Portland Cement, saturated surface dry river sand as fine aggregate, gravel with a maximum nominal size of $9.5 \mathrm{~mm}$ as coarse aggregate, and potable tap water were used in all mixes. Slump was maintained at $150 \mathrm{~mm}$ for all mixes. Where ground tire rubber was used, it was used as a $15 \%$ replacement of the coarse aggregate by mass which produce $25 \%$ more fresh concrete by volume. This meant that the mass \% of ground rubber in the mix relative to cement was of $47 \%$. The ground tire rubber had a specific gravity of 1.1 and a maximum nominal size of $9.5 \mathrm{~mm}$ (Figure 1). Its gradation curve is given in Figure 3. The size of the recycled glass materials was between 297-840 micron 
TABLE 1: Mix proportions and fresh properties.

\begin{tabular}{|c|c|c|c|c|}
\hline \multicolumn{5}{|c|}{ Mixture proportions } \\
\hline Material & $\begin{array}{l}\text { Control Mix M0 } \\
\qquad\left(\mathrm{m}^{3}\right)\end{array}$ & $\begin{array}{l}\text { RMC Mix M1 } \\
\left(1.25 \mathrm{~m}^{3}\right)\end{array}$ & $\begin{array}{l}\text { RMC Mix M2 } \\
\left(1.25 \mathrm{~m}^{3}\right)\end{array}$ & $\begin{array}{c}\text { RMC Mix M3 } \\
\left(1.25 \mathrm{~m}^{3}\right)\end{array}$ \\
\hline Cement $(\mathrm{kg})$ & 360 & 360 & 360 & 360 \\
\hline Coarse aggregate $(\mathrm{kg})$ & 1130 & 960.5 & 960.5 & 565 \\
\hline Fine aggregate $(\mathrm{kg})$ & 580 & 580 & 580 & 290 \\
\hline Water $(\mathrm{kg})$ & 180 & 180 & 180 & 180 \\
\hline Defoaming agent $(\mathrm{mL})$ & 0 & 0 & 360 & 360 \\
\hline Air entrainment agent $(\mathrm{mL})$ & 90 & 0 & 0 & 0 \\
\hline Ground tire rubber $(\mathrm{kg})$ & 0 & 169.5 & 169.5 & 169.5 \\
\hline Recycled concrete $(\mathrm{kg})$ & 0 & 0 & 0 & 395.5 \\
\hline Crushed glass $(\mathrm{kg})$ & 0 & 0 & 0 & 290 \\
\hline Superplasticizer $(\mathrm{mL})$ & 0 & 0 & 0 & 300 \\
\hline \multicolumn{5}{|l|}{ Fresh properties } \\
\hline Slump (mm) & 150 & 150 & 150 & 150 \\
\hline Air content (\%) & 4.5 & 16.0 & 5.5 & 9 \\
\hline Measured density $\left(\mathrm{kg} / \mathrm{m}^{3}\right)$ & 2350 & 2100 & 2300 & 2050 \\
\hline
\end{tabular}

(Figure 2). The defoaming agent used was Rhodoline 1010 manufactured by Brenntag Industries. The air entrainment admixture used was Darex II manufactured by Grace Construction Products. The recycled coarse aggregate used in the study had a maximum nominal size of $9.5 \mathrm{~mm}$, and it had been washed and brought to SSD conditions before mixing. Batches were prepared as per ASTM C192.

Slump tests (ASTM C143) and air content tests (ASTM C173) were carried out on fresh mixture and the values are reported in Table 1. The mixes containing ground tire rubber were more difficult to work with and showed slightly more segregation in the fresh state.

From each mix, ten standard $100 \mathrm{~mm} \times 200 \mathrm{~mm}$ cylinders were cast for a total of 40 cylinders. Cylinders were moist cured for at least 28 days following which compressive strength tests were performed as per ASTM C69. An $890 \mathrm{kN}$ capacity Forney Compressive Testing Machine was used. From each batch, five specimens were tested at an age of 7 days, and the remaining five were tested at an age of 28 days. For the tests at 28 days, elastic modulus values were also determined using a deformation cage as per ASTM C469.

Air content values in Table 1 indicated that while the air content was reduced as a result of defoamer addition, one needed to further characterize the nature of air that was left behind. To gain this understanding, six $75 \mathrm{~mm} \times$ $100 \mathrm{~mm} \times 405 \mathrm{~mm}$ prismatic beams were cast from each mix, for a total of 24 such beams, for freeze-thaw testing. For Mixes M1 and M2 following a cyclic exposure to freezing and thawing in an automated freeze-thaw chamber, damage was quantified using ultrasonic pulse velocity (UPV) measurements (ASTM C597) and compared with the Control Mix M0. For Mix M3, ASTM C666 was followed, and the damage was quantified using the Resonant Frequency Test (ASTM C215). The change in the resonant frequency of each specimen was monitored at regular intervals of every 35 cycles using a Sonometer. The dynamic modulus of elasticity was determined by measuring the fundamental transverse frequency of the sample at each test interval. The relative dynamic modulus of elasticity and the Durability Factors were calculated according to ASTM C666.

Finally, one $300 \mathrm{~mm} \times 100 \mathrm{~mm}$ round panel was cast for control Mix M0 and RMC Mix M3 for a total of two such panels, on which torrent permeability tests were performed [27]. Torrent is a surface permeability test which determines the ease with which concrete surface can get saturated.

\section{Results}

4.1. Strength. The strengths measured at 7 and 28 days are given, respectively, in Figures 4 and 5(a). In Figure 5(b), the 28-day elastic moduli are also plotted.

When mixes M0 and M1 are compared, a steep reduction in the compressive strength at both ages is apparent. This has been reported often by others and is most likely related to the increased air content (from $4.5 \%$ to $16.0 \%$ ) and an apparent lack of bond between the tire rubber and the paste. The addition of a defoaming agent does bring down the air significantly from $16 \%$ to $5.5 \%$ (almost to the level of control concrete), but the compressive strength in the defoamed mixture (M2) increased only marginally. It seems likely that the loss of strength in mixtures with scrap tires is not only due to the increased air but also due to poor bond between scrap tire and cement paste. It is also conceivable that the 5.5\% air left in Mix M2 is of a different nature. To try and determine the type and nature of the voids present in concrete containing ground rubber, we turn to fracture mechanics.

Assuming that linear elastic fracture mechanics applies to concrete, the condition determining unstable tensile fracture in Mode I when an internal flaw of size $2 a$ is present is given by

$$
K_{\mathrm{IC}}=Y \sigma_{c} \sqrt{\pi a},
$$

where $K_{\text {IC }}$ is Plain Strain Fracture Toughness (i.e., Critical Stress Intensity Factor) in Mode I, $Y$ is a dimensionless 


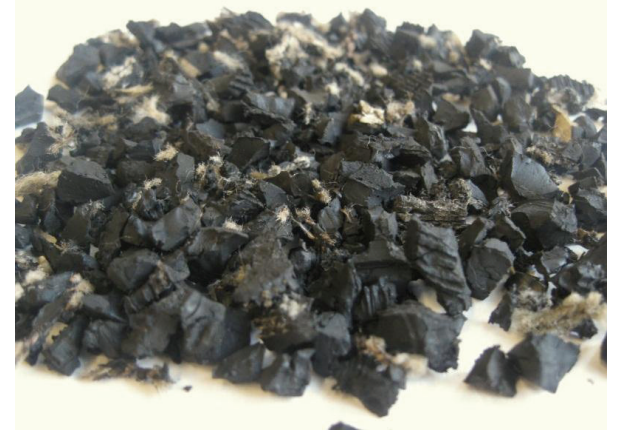

Figure 1: Recycled ground rubber.

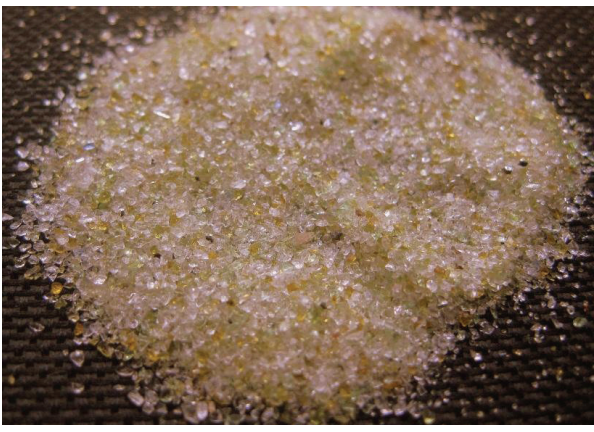

FIgURE 2: Recycled glass.

parameter that depends on the specimen and crack geometries, and $\sigma_{c}$ is the failure stress.

Equation (1) can also be written in the form of maximum allowable flaw size $\left(a_{c}\right)$ that will trigger an unstable fracture as

$$
a_{c}=\frac{1}{\pi}\left(\frac{K_{I C}}{\sigma_{c} Y}\right)^{2} .
$$

For concrete, $K_{\text {IC }}$ can be taken as $0.2 \mathrm{MPa} \mathrm{m}^{1 / 2}$ [28]. For a finite cylinder with a flaw much smaller than the cylinder width, $Y$ can be taken as 1.0 [29].

Finally, the tensile strength of concrete $\left(\sigma_{c}\right)$ can be estimated from its compressive strength $\left(f_{c}^{\prime}\right)$ as [30]

$$
\sigma_{c}=0.94 \sqrt{f_{c}^{\prime}} .
$$

Substituting the appropriate values into (2), we find that for

(a) M0, $a_{c}=0.48 \mathrm{~mm}$, or the allowable flaw size $=2 a_{c}=$ $0.96 \mathrm{~mm}$,

(b) M1, $a_{c}=2.05 \mathrm{~mm}$, or the allowable flaw size $=2 a_{c}=$ $4.10 \mathrm{~mm}$.

Interestingly, approximately $40 \%$ of the ground rubber in the mix has a nominal length of around $4 \mathrm{~mm}$ (Figure 3 ) which corresponds to the approximate predicted flaw size in M1. It implies, therefore, that most of the air in the mixes containing ground rubber is trapped at the interfaces between rubber and concrete and not entrained in the

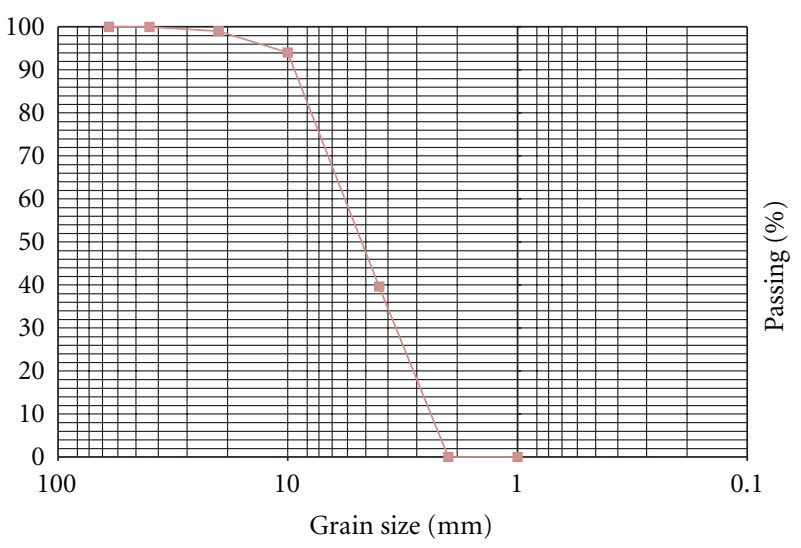

- Gradation curve

Figure 3: Ground tire gradation curve.

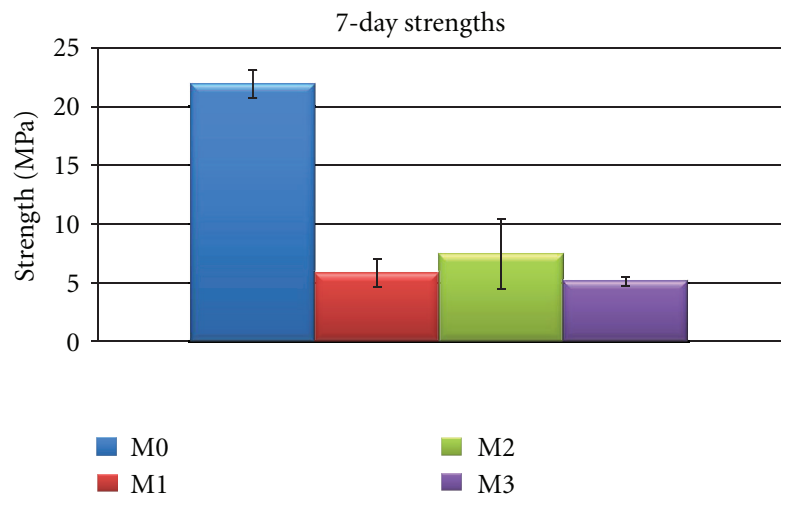

FIgURE 4: 7-day compressive strengths.

cement-paste. This entrapment of air would lead to poor bond between rubber and concrete and a dramatic reduction in the compressive strength. Even for mixes where defoaming agent was added although there was an overall reduction in the air content down to the level of Control concrete, the remaining air still gathered at the rubber-concrete interface and continued to weaken the bond and persistently lowered the strength. The concept is illustrated in Figure 6. Notice that the Mix M1 in Figures 6(b) entrapped significantly greater amounts of air over Mix M0 in Figure 6(a). While the Mixes M2 and M3 saw improvements and air contents over M1, the remaining air still persistently congregated at the interfaces, and no appreciable strength gains over M0 were achievable. Air in M1, M2, and M3 continued to reside in flocculated, continuous and elongated voids causing large stress concentration and drop of strength. This also conceivably increased the permeability to water and the ease with which M1, M2, and M3 became saturated and depicted lower resistance to freezing and thawing as will be seen later.

Bringing other recycled materials in the mix (recycled aggregate and crushed glass) further increases the air from $5.5 \%$ to $9 \%$. This is expected as recycled aggregate do entrap air by themselves. This increase in air is also accompanied 


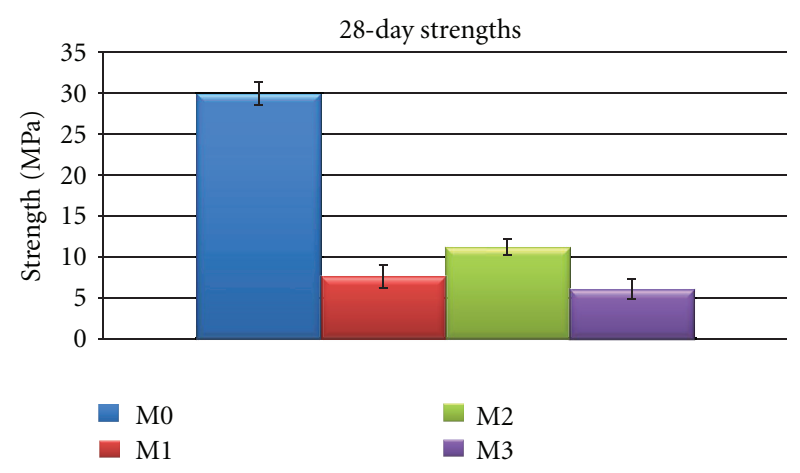

(a)

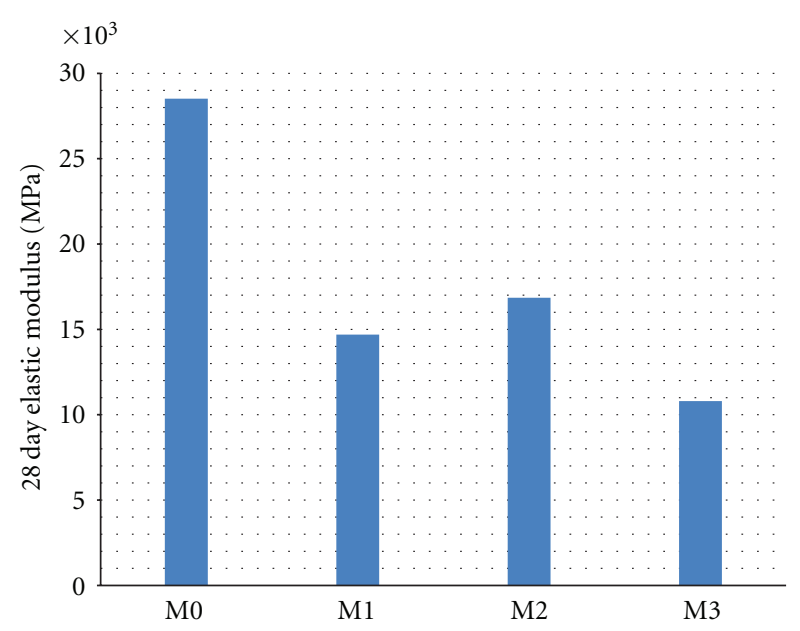

(b)

FIGURE 5: (a) 28-day compressive strengths, (b) 28-day elastic moduli.

by a corresponding drop in the compressive strength (and modulus of Mix M3) at both ages.

Based on the data obtained, the following empirical equation (4) is proposed to try and estimate the Elastic Modulus of Ground Rubber Concrete based on its strength and density:

$$
E=0.001 \sigma^{0.5} \gamma^{2}
$$

where $E$ is the elastic modulus of concrete with ground rubber $(\mathrm{MPa}), \sigma$ is the compressive strength of ground rubber concrete $(\mathrm{MPa})$, and $\gamma$ is the density of concrete $\left(\mathrm{kg} / \mathrm{m}^{3}\right)$.

ACI 318 has established an empirical relationship, between Elastic Modulus, Strength, and Density as:

$$
E=0.043 \gamma^{1.5} \sigma^{0.5}
$$

Using these two equations, the predicted results versus the actual results are shown in Figure 7.

Therefore, although the data set with which (4) was derived is quite limited, it compares quite well with not only measured results, but also with predictions from ACI 318 which is based on a large amount of empirical data. Therefore, we believe it still may be used as a basis for future work to try and formulate the relationship between strength, density, and elastic modulus for concrete containing ground rubber.

4.2. Freeze Thaw Resistance. In order to further understand the nature of air voids in concrete carrying scrap tire and other recycled materials, freeze-thaw tests were performed as per ASTM C666. Freeze thaw resistance was assessed using ultrasonic pulse velocity measurements for Mixes M0, M1 and M2, while the Resonant Frequency measurements were carried out on Mixes M0 and M3. Photographs of specimens after 210 cycles of freezing and thawing are given in Figure 8.

Notice that Mixes M1 and M2 both containing rubber show a significantly lower initial UPV reading compared to the control, a difference that persists over the entire duration of the freeze-thaw test. This finding is reasonable, as the addition of rubber is believed to have a damping effect on wave propagation, mainly due to the provision of extra air voids [31, 32]. M2 initially does not have as much of a decrease in UPV readings compared to the control, as the air content is almost the same as that of mix M0.

Notice in Figure 9 that while the control concrete was able to sustain 300 cycles of freezing and thawing without any drop in the ultrasonic pulse velocity reading, the addition of the rubber (Mix M1) had adverse consequences on UPV starting at a very low number of freeze-thaw cycles. Additionally these samples exhibited severe scaling (Figure 8). The mix with defoaming agent fared marginally better in comparison to the nondefoamed concrete, but ultimately still showed a marked decrease in UPV in a freeze-thaw environment. The result of the UPV decrease will be correlated later with a drop in dynamic modulus as determined in ASTM C666 that were performed on Mixes M0 and M3. Such a correlation has been previously attempted by Mirmiran and Wei [33] and by Yildiz and Ugur [34]. More specifically, UPV measurement were carried out on ASTM C666 at failure for Mix M3 and that value of UPV was used to determine freeze-thaw failure cycle for Mixes M1 and M2. This was considered to be an acceptable approach as Mixes M1, M2, and M3 all had very similar 28-day strength.

In Figure 10, the freeze-thaw durability of Mix M3 is compared with control Mix M0 using the ASTM C666 specified criteria of resonant frequency (and thereby the dynamic modulus) and the resulting durability factor (Figure 11). Notice that Mix M3 sustained far greater number of cycles than Mixes M1 and M2 but still did not approach the performance of the control and did not sustain the required 300 cycles.

For Mix 3 the specimen failed after 210 cycles according to ASTM C666 since the durability factor dropped below 60 percent. The UPV value was recorded at this point as being $3050 \mathrm{~m} / \mathrm{s}$ (Figure 12). In comparison, Mix 1 reached this failure point after 116 cycles and Mix 2 failed after 171 cycles. Defoamer appears to have a positive effect, as it increases the time to failure by to $32.2 \%$ compared to the defoamer-free mix.

One of the reasons why a particular concrete mix would perform poorly under freeze-thaw cycling is its void structure. Concrete which contains entrained air will be more 


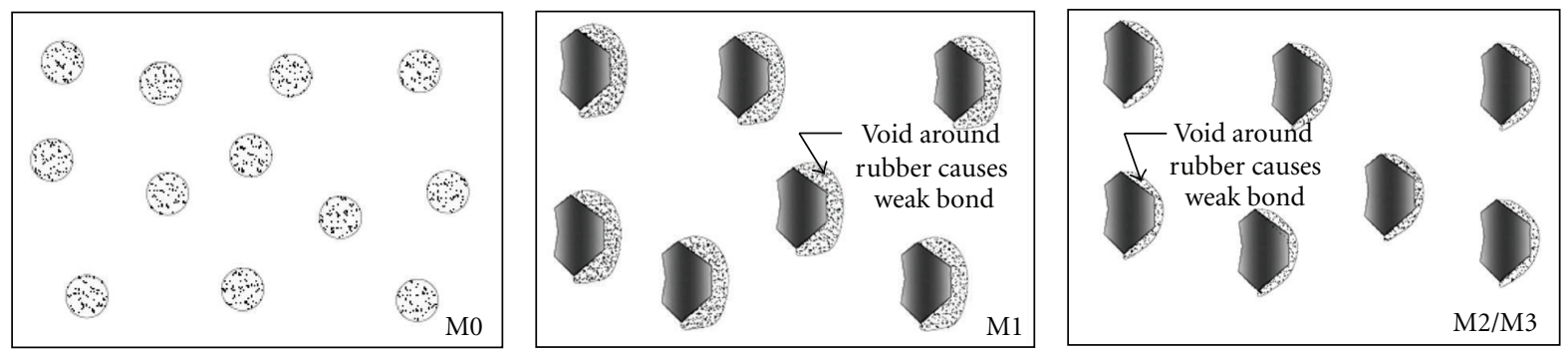

Figure 6: Comparison different shapes of voids in concrete.

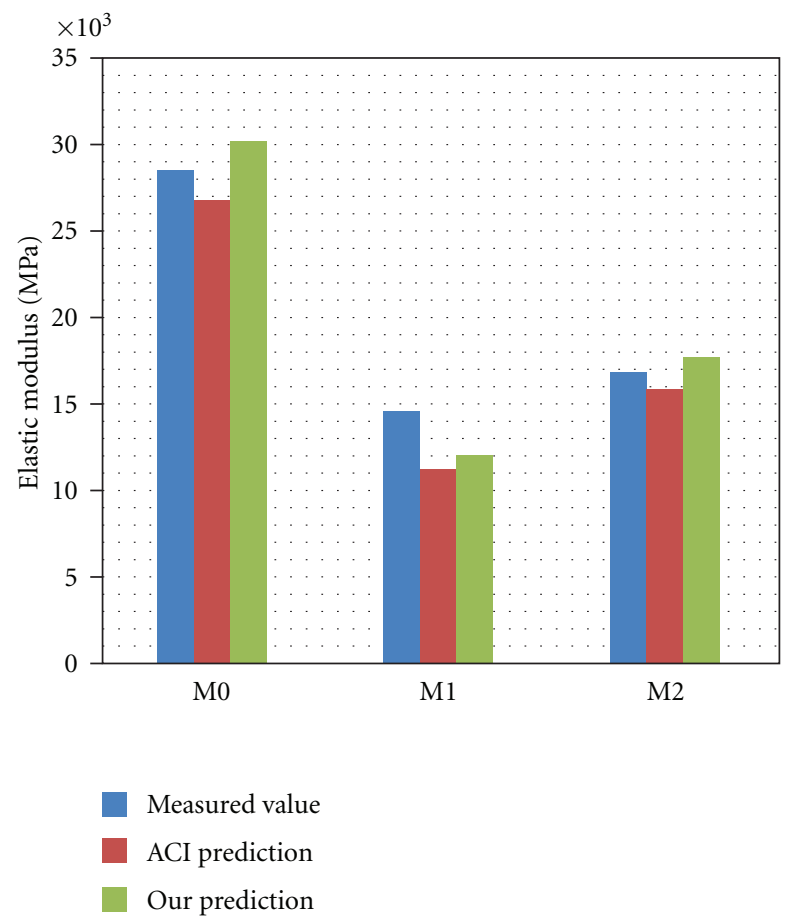

Figure 7: Predicted results versus actual results using (4) and (5).

durable and have more freeze-thaw resistance. Entrained air produces discrete, nearly spherical bubbles in the cement paste so that no channels for the flow of water are formed and the permeability of the concrete is not increased [35]. Excess water is able to escape into these air filled voids and damage of concrete due to freeze thaw conditions will not occur. Entrapped air will form larger, interconnected voids, may lower concrete strength, and subsequently lower freezethaw resistance.

To assess the possibility, torrent permeability tests were performed and the results are given in Table 2. Notice that Mix M3 was far more permeable compared to control Mix M0. The increase in permeability is further evidence that the additional air voids formed due to the inclusion of ground rubber in the mix is of the nonentrained nature and coagulating at the rubber-concrete interface as proposed earlier in this paper.

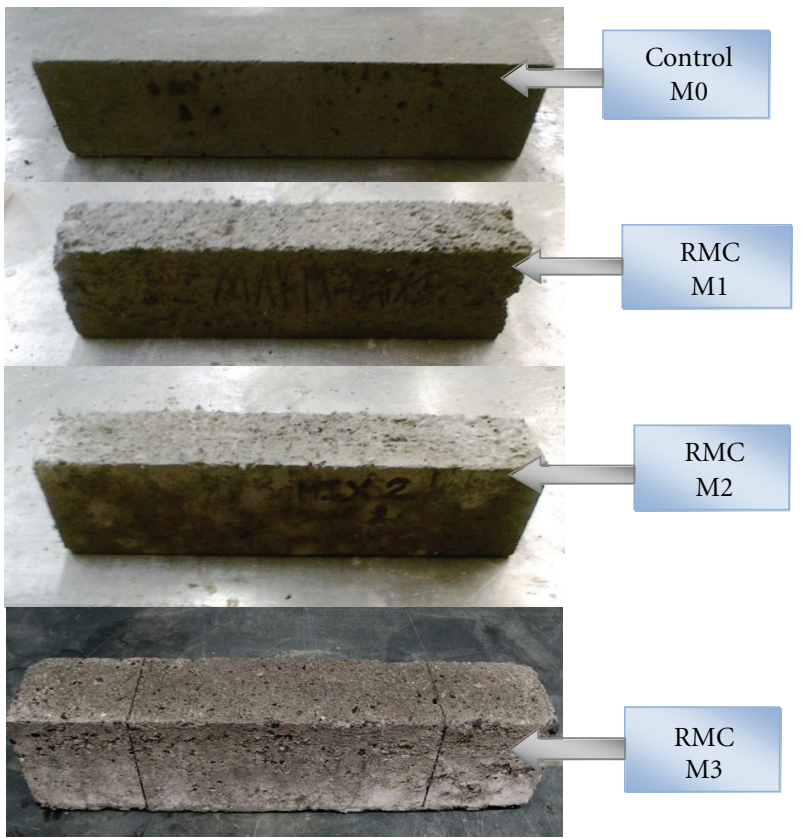

Figure 8: Beam samples after 210 freeze-thaw cycles.

TABLE 2: Torrent permeability measurements.

\begin{tabular}{lcc}
\hline & Control Mix M0 & RMC Mix M3 \\
\hline $\begin{array}{l}\text { Permeability coefficient } \\
(\mathrm{kT})\left(\mathrm{m}^{2}\right)\end{array}$ & $0.063 \times 10^{-16}$ & $0.157 \times 10^{-16}$ \\
\hline
\end{tabular}

\section{Conclusions and Recommendations}

(1) Addition of ground tire rubber into a concrete mix greatly increases the air content of the mix, but it seems possible to reduce the air content to acceptable levels by using a defoamer.

(2) When recycled aggregates and glass are brought into a mix containing ground tire rubber, air contents move up again, and the defoamer is less effective.

(3) In concrete mixtures containing ground tire rubber, while a defoaming agent may reduce the air appreciably, a proportional increase in the compressive strength is not noticed. This implies that the remaining air in the defoamed mixture is of poor quality. Specifically, the voids appear to be less dispersed, 


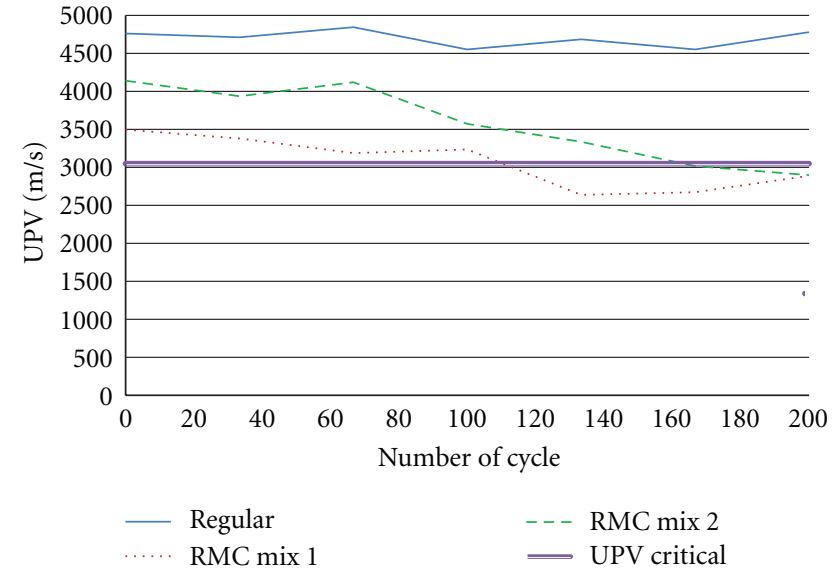

FIGURE 9: Freeze-thaw resistance using UPV values as a function of cycles.

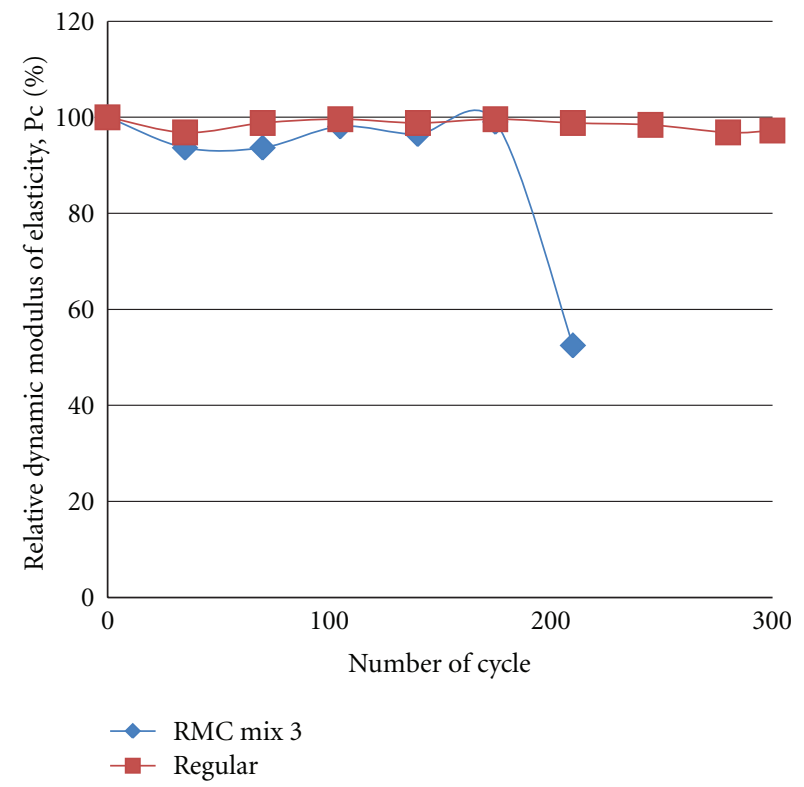

FIgURe 10: Average relative dynamic modulus of elasticity versus freeze-thaw cycles.

elongated, and coagulate at the rubber-concrete interface, thereby affecting the bond and reducing overall strength. These observations were further supported by freeze-thaw and permeability testing.

(4) Freeze-thaw testing indicated that concrete carrying ground tire rubber fares poorly under freeze-thaw, but the performance can be marginally improved using a defoamer. The freeze-thaw performance stabilizes when other recycled materials such as recycled aggregate and crushed glass are added to the mix.

(5) While it is probably not possible to use the concrete mixtures developed here for structural elements where high strength and durability under loads are required, they may still be used in nonstructural applications such as partition walls, road barriers, pavements, or low-strength foundations.

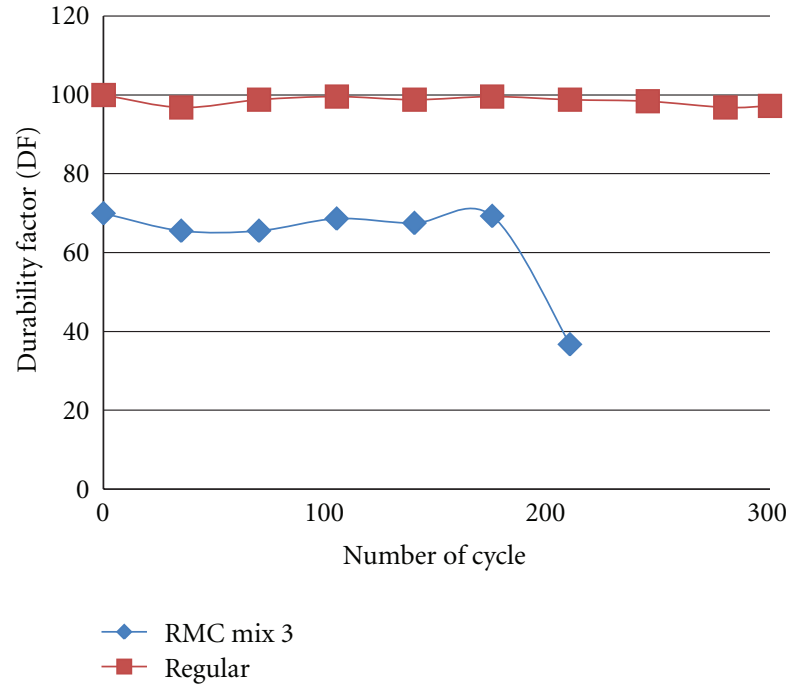

FIGURE 11: Average durability factor versus no freeze-thaw cycles.

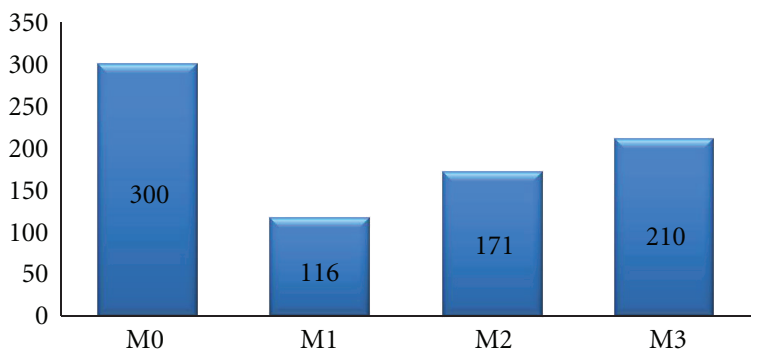

- Number of Cycles

Figure 12: Number of freeze-thaw cycles survived $\left(N_{f}\right)$ by various mixes.

\section{Acknowledgments}

The authors wish to acknowledge the help of Mr. Patrick McConnell for supplying the recycled materials used in this study. Also, they would like to thank Mr. Adrien Drochon, Mr. Sylvian Lioux, Ms. Saakshi Mahajan, and Ms. Roxanna Mousavi for their assistance in the lab with specimen preparation and testing.

\section{References}

[1] L. Lemay, "Concrete and climate change: how does concrete stack up against other building materials," Concrete Infocus, vol. 7, no. 2, pp. 38-43, 2008.

[2] C. Meyer, "The greening of the concrete industry," Cement and Concrete Composites, vol. 31, no. 8, pp. 601-605, 2009.

[3] F. Collins, "Inclusion of carbonation during the life cycle of built and recycled concrete: influence on their carbon footprint," International Journal of Life Cycle Assessment, vol. 15, no. 6, pp. 549-556, 2010.

[4] G. Li, M. A. Stubblefield, G. Garrick, J. Eggers, C. Abadie, and B. Huang, "Development of waste tire modified concrete," Cement and Concrete Research, vol. 34, no. 12, pp. 2283-2289, 2004. 
[5] I. B. Topçu and M. Canbaz, "Properties of concrete containing waste glass," Cement and Concrete Research, vol. 34, no. 2, pp. 267-274, 2004.

[6] S. M. Levy and P. Helene, "Durability of recycled aggregates concrete: a safe way to sustainable development," Cement and Concrete Research, vol. 34, no. 11, pp. 1975-1980, 2004.

[7] C. S. Poon, Z. H. Shui, L. Lam, H. Fok, and S. C. Kou, "Influence of moisture states of natural and recycled aggregates on the slump and compressive strength of concrete," Cement and Concrete Research, vol. 34, no. 1, pp. 31-36, 2004.

[8] T. C. Hansen and H. Narud, "Strength of recycled concrete made from crushed concrete coarse aggregate," Concrete International, vol. 5, no. 1, pp. 79-83, 1983.

[9] T. C. Hansen, "Recycled aggregates and recycled aggregate concrete second state-of-the-art report developments 19451985," Materials and Structures, vol. 19, no. 3, pp. 201-246, 1986.

[10] J. M. Khatib, "Properties of concrete incorporating fine recycled aggregate," Cement and Concrete Research, vol. 35, no. 4, pp. 763-769, 2005.

[11] S. B. Park, B. C. Lee, and J. H. Kim, "Studies on mechanical properties of concrete containing waste glass aggregate," Cement and Concrete Research, vol. 34, no. 12, pp. 2181-2189, 2004.

[12] T. R. Naik and Z. Wu, "Crushed post-consumer glass as a partial replacement of sand in concrete," in Proceedings of the 5th CANMET/ACI International Conference on Recent Advances of Concrete Technology, SP-200, V. M. Malhotra, Ed., pp. 553-568, American Concrete Institute, Farmington Hills, Mich, USA, 2001.

[13] A. I. Isayev, K. Khait, and S. K. De, Rubber Recycling, CRC Press, Boca Raton, Fla, USA, 2005.

[14] N. N. Eldin and A. B. Senouci, "Rubber-tire particles as concrete aggregate," Journal of Materials in Civil Engineering, vol. 5, no. 4, pp. 478-496, 1993.

[15] R. Siddique and T. R. Naik, "Properties of concrete containing scrap-tire rubber-an overview," Waste Management, vol. 24, no. 6, pp. 563-569, 2004.

[16] M. Nehdi and A. Khan, "Cementitious composites containing recycled tire rubber: overview of engineering properties and potential applications," Journal of Cement, Concrete and Aggregates, vol. 23, no. 1, pp. 3-10, 2001.

[17] F. Hernández-Olivares, G. Barluenga, M. Bollati, and B. Witoszek, "Static and dynamic behaviour of recycled tyre rubber-filled concrete," Cement and Concrete Research, vol. 32, no. 10, pp. 1587-1596, 2002.

[18] B. Huang, G. Li, S. S. Pang, and J. Eggers, "Investigation into waste tire rubber-filled concrete," Journal of Materials in Civil Engineering, vol. 16, no. 3, pp. 187-194, 2004.

[19] E. Ganjian, M. Khorami, and A. A. Maghsoudi, "Scraptyre-rubber replacement for aggregate and filler in concrete," Construction and Building Materials, vol. 23, no. 5, pp. 18281836, 2009.

[20] H. A. Toutanji, "The use of rubber tire particles in concrete to replace mineral aggregates," Cement and Concrete Composites, vol. 18, no. 2, pp. 135-139, 1996.

[21] M. K. Batayneh, I. Marie, and I. Asi, "Promoting the use of crumb rubber concrete in developing countries," Waste Management, vol. 28, no. 11, pp. 2171-2176, 2008.

[22] A. R. Khaloo, M. Dehestani, and P. Rahmatabadi, "Mechanical properties of concrete containing a high volume of tire-rubber particles," Waste Management, vol. 28, no. 12, pp. 2472-2482, 2008.
[23] B. S. Mohammed, "Structural behavior and $\mathrm{m}-\mathrm{k}$ value of composite slab utilizing concrete containing crumb rubber," Construction and Building Materials, vol. 24, no. 7, pp. 12141221, 2010.

[24] B. Z. Savas, S. Ahmad, and D. Fedroff, "Freeze-thaw durability of concrete with ground waste tire rubber," Transportation Research Record, no. 1574, pp. 80-88, 1997.

[25] D. Fedroff, S. Ahmad, and B. Z. Savas, "Mechanical properties of concrete with ground waste tire rubber," Transportation Research Board, no. 1532, pp. 66-72, 1996.

[26] Z. K. Khatib and F. M. Bayomy, "Rubberized Portland cement concrete," Journal of Materials in Civil Engineering, vol. 11, no. 3, pp. 206-213, 1999.

[27] M. Romer, "Effect of moisture and concrete composition on the Torrent permeability measurement," Materials and Structures, vol. 38, no. 5, pp. 541-547, 2005.

[28] W. D. Callister, Materials Science and Engineering: An Introduction, John Wiley \& Sons, New York, NY, USA, 5th edition, 2000.

[29] D. P. Rooke and D. J. Cartwright, Compendium of Stress Intensity Factors, Hillingdon Press, Uxbridge, UK, 1976.

[30] S. Mindess, J. F. Young, and D. Darwin, Concrete, Prentice Hall, Upper Saddle River, NJ, USA, 2nd edition, 2002.

[31] K. B. Najim and M. R. Hall, "A review of the fresh/hardened properties and applications for plain- (PRC) and selfcompacting rubberised concrete (SCRC)," Construction and Building Materials, vol. 24, no. 11, pp. 2043-2051, 2010.

[32] B. S. Mohammed, N. J. Azmi, and M. Abdullahi, "Evaluation of rubbercrete based on ultrasonic pulse velocity and rebound hammer tests," Construction and Building Materials, vol. 25, no. 3, pp. 1388-1397, 2011.

[33] A. Mirmiran and Y. Wei, "Damage assessment of FRPencased concrete using ultrasonic pulse velocity," Journal of Engineering Mechanics, vol. 127, no. 2, pp. 126-135, 2001.

[34] K. Yildiz and L. O. Ugur, "Examination of durability of high performance concrete that has been subjected to $\mathrm{MgSO}_{4}$ and $\mathrm{NaCl}$ corrosion against freezing and thawing," Scientific Research and Essay, vol. 4, no. 9, pp. 929-935, 2009.

[35] A. M. Neville, Properties of Concrete, Pearson Education, New Delhi, India, 4th edition, 1995. 

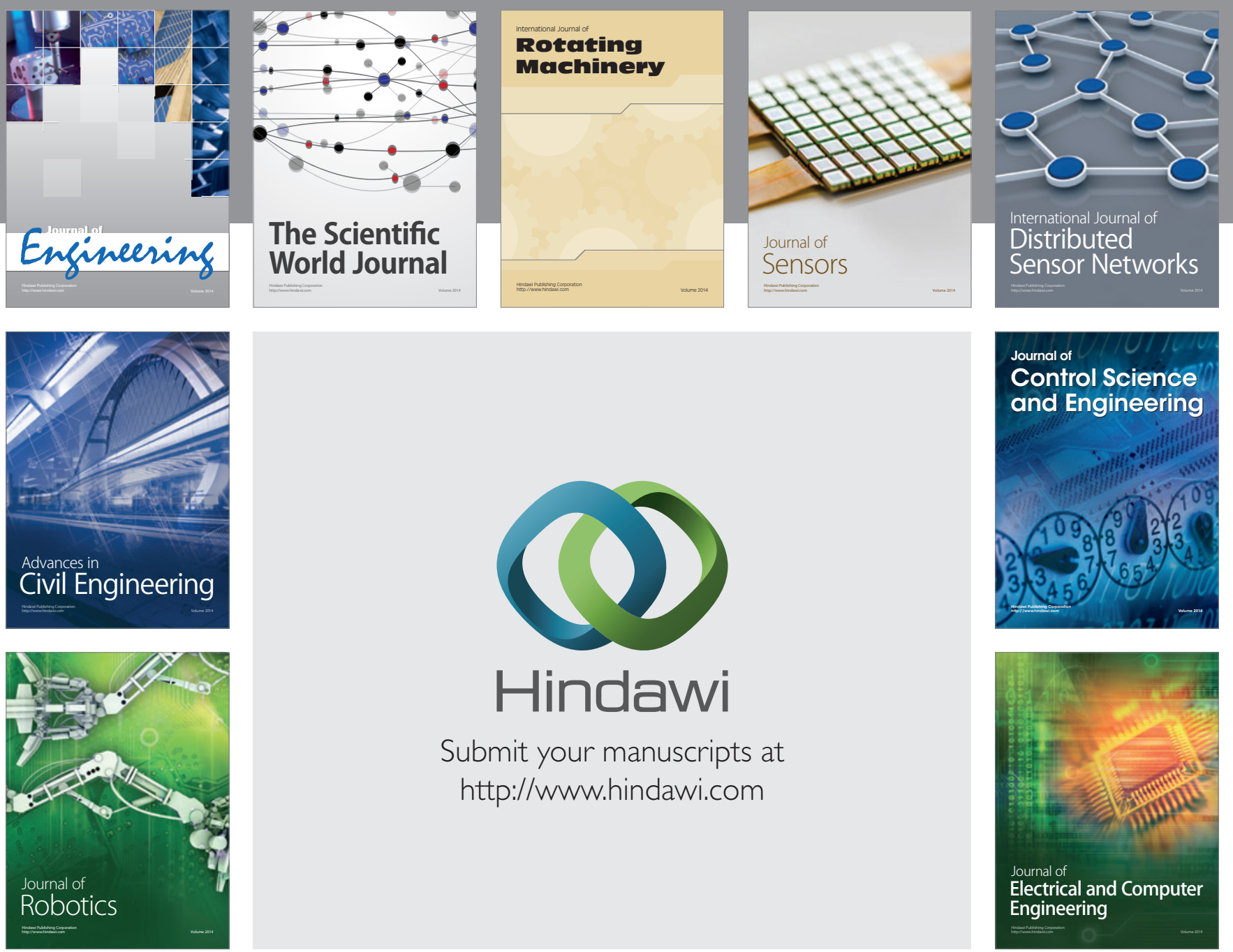

Submit your manuscripts at

http://www.hindawi.com
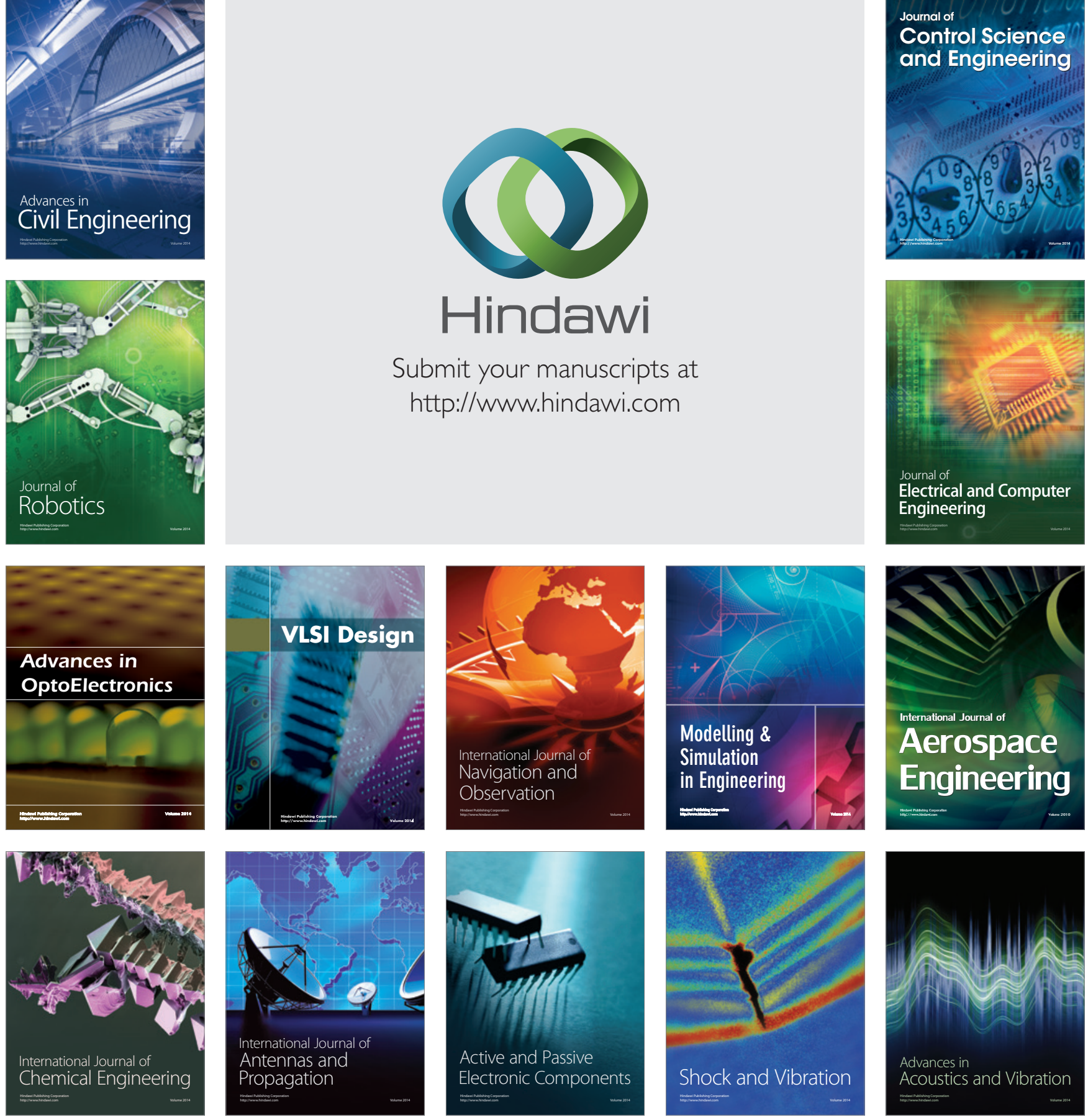